\title{
DINÂMICA INICIAL DA COMPOSIÇÃO FLORÍSTICA DE UMA ÁREA RESTAURADA NA REGIÃo DO PONTAL DO PARANAPANEMA, SÃo PAULO, BRASIL $^{1}$
}

\author{
Elisangela Ronconi Rodrigues ${ }^{2}$, Reinaldo Monteiro ${ }^{3}$ e Laury Cullen Junior ${ }^{4}$
}

\begin{abstract}
RESUMO - O Pontal do Paranapanema, extremo oeste do Estado de São Paulo, é marcado pela recente devastação florestal, e ações visando à recuperação de áreas onde outrora havia cobertura florestal tornam-se indispensáveis para a conservação da biodiversidade na região, principalmente quando se trata de áreas de Reserva Legal ou Preservação Permanente. Diante do exposto, esta pesquisa teve como objetivo analisar a dinâmica inicial da composição florística em uma área de Reserva Legal restaurada. O trabalho foi realizado no assentamento Nova Esperança, Município de Euclides da Cunha Paulista, em uma área de 26,75 ha. O levantamento das espécies foi realizado pelo método de parcelas (16 parcelas de 20 × $30 \mathrm{~m}$ ) em duas fases distintas do plantio, e as análises foram feitas utilizando-se o software Fitopac. Os resultados evidenciaram diminuição da biodiversidade pela alta mortalidade de espécies, levando à conclusão de que em projetos de restauração as intervenções são necessárias para a manutenção do plantio mesmo em sua fase inicial.
\end{abstract}

Palavras-chave: Reserva Legal, Florística, fitossociologia e Restauração.

\section{INITIAL DYNAMICS OF FLORISTIC COMPOSITION IN A RESTORESD AREA IN THE REGION OF PONTAL DO PARANAPANEMA, SÃO PAULO STATE, BRAZIL}

\begin{abstract}
The Pontal do Paranapanema Region is located in the western range of the State of São Paulo is characterized by recent forest destruction and actions are needed for forest restorations and conservation of biodiversity in the region, principally when if treated of areas of Legal Reserve or Permanent Preservation. Before of the exposed this research had it objective analyze the dynamics initial from floristic composition an area of Legal Reserve restored. This work was realized into the Nova Esperança settlement, city of Euclides da Cunha Paulista, an area of 26,75 ha. The lifting from the species was realized at method of parcels $(16$ parcels of $20 \times 30 \mathrm{~m}$ ) into two phases differentiate of the plantation, and the analisys have been using Fitopac software. The results they show only one decrease from biodiversity by high mortality of species, taking the conclusive what projects of restoration, intervention so necessary about to conservation of the plantation even in initial phase.
\end{abstract}

Keywords: Legal Reserve. Floristic, phytosociological analysis and Restoration.

\section{INTRODUÇÃO}

Dentre as formações florestais brasileiras, a Floresta Atlântica lato senso (que envolve uma série de formações como a Floresta Ombrófila Densa, a Floresta Ombrófila Mista e a Floresta Estacional Semidecidual, além de ecossistemas associados) foi a que sofreu maior devastação devido à ocupação populacional e expansão das fronteiras agropecuárias, restando, atualmente, algo em torno de 5 a 7\% de sua área original (REIS et al., 1999; MYERS et al., 2000).

A Floresta Estacional Semidecidual foi o tipo florestal mais devastado no Estado de São Paulo. A devastação dessas florestas ocorreu associada à expansão da fronteira agrícola, já que ocupavam os solos de maior fertilidade

\footnotetext{
${ }^{1}$ Recebido em 25.03.2009 e aceito para publicação em 02.03.2010.

${ }^{2}$ Centro Universitário UniFMU, Brasil. E-mail: <elisangelaronconi@terra.com.br>.

${ }^{3}$ Universidade Estadual Paulista Júlio de Mesquita Filho, UNESP, Brasil. E-mail: <reimonte@rc.unesp.br>.

${ }^{4}$ Instituto de Pesquisas Ecológicas, IPÊ, Brasil. E-mail: <lcullen@stetnet.com.br>.
} 
no Estado de São Paulo, em regiões com relevo favorável à agricultura. Dos fragmentos remanescentes, poucos têm área representativa e encontram-se preservados. Assim, áreas disponíveis para pesquisa sobre floresta estacional semidecidual no Estado de São Paulo são, portanto, poucas e os dados disponíveis, escassos (DURIGAN et al., 2000).

A fragmentação é, na grande maioria das vezes, um processo antrópico de ruptura da continuidade das unidades de uma paisagem, resultando em mudanças na composição e diversificação das comunidades que nela habitam. Isso acaba por isolar e reduzir as áreas que são propícias à sobrevivência das populações, causando extinções locais, reduzindo a variabilidade genética dessas e, consequentemente, levando à perda de biodiversidade (METZGER, 1999).

Diante desse panorama, emergiu no século passado o pensamento ambientalista, trazendo à tona não só a necessidade de preservar os fragmentos florestais, como também de recompor áreas onde outrora existia vegetação nativa. Isto abriu espaço para a restauração ecológica, tendência atual em recuperação de áreas degradadas, definida por Engel e Parrota (2001) como a ciência, prática e arte de assistir e manejar a recuperação da integridade ecológica dos ecossistemas, incluindo um nível mínimo de biodiversidade e de variabilidade na estrutura e funcionamento dos processos ecológicos e considerando seus valores ecológicos, econômicos e sociais.

A restauração de sítios degradados não é, entretanto, um processo simples. Após sofrer distúrbio, uma área degradada perde, juntamente com a sua vegetação, os seus meios bióticos de regeneração, impedindo, assim, o retorno natural do ecossistema à sua condição inicial. Nesses casos, é necessária forte intervenção antrópica para que sejam superados impedimentos existentes para a recuperação natural do ecossistema, possibilitando o retorno da área à condição pré-existente ou a algum estado estável permanente (ANAND; DESROCHERS, 2000; RODRIGUES; GANDOLFI, 2000).

Atualmente, o plantio de mudas tem sido o método mais utilizado em projetos de restauração, e seu sucesso depende de vários fatores, entre os quais se destacam: o grau de modificação em relação ao ambiente natural, as espécies a serem utilizadas, a obtenção de propágulos, a distribuição dessas espécies no novo ambiente e a participação de comunidade humana (FERREIRA et al., 2007)

Por fim, o monitoramento e avaliação dos projetos com essa finalidade tornam-se fundamentais para o avanço do conhecimento científico-tecnológico, o que subsidiará novas propostas e norteará a tomada de decisões. Nesse sentido, avaliar a dinâmica da composição florística na fase inicial do projeto é importante ferramenta para monitoramentos no longo prazo, permitindo acompanhar o desenvolvimento da comunidade implantada e a sua sucessão e estabelecimento ao longo do tempo.

Diante do exposto, este pesquisa teve como objetivo acompanhar o estabelecimento da vegetação em uma área de Reserva Legal restaurada no Assentamento Nova Esperança, município de Euclides da Cunha Paulista, região do Pontal do Paranapanema.

\section{METODOLOGIA}

\subsection{Caracterização da Área de Estudo}

O Pontal do Paranapanema localiza-se no extremo Oeste de São Paulo, entre as confluências dos rios Paraná e Paranapanema, sendo essa a segunda região mais pobre do Estado, marcada pela recente e voraz devastação florestal, intensificada a partir da década de 1950, que transformou a paisagem da região em extensas áreas de monocultivos e pastagens (VALLADARES-PADUA et al., 2002).

A vegetação característica da região é classificada como Floresta Estacional Semidecidual, inserida nos domínios da Mata Atlântica, sendo por isso popularmente chamada de "Mata Atlântica do Interior”. Ela está predominantemente fixada sobre Latossolo Vermelho, derivado de rochas sedimentares, formadas principalmente por arenito-caiuá, resultante da compactação da areia (ATLAS INTERATIVO DO PONTAL DO PARANAPANEMA, 2001).

No que tange aos aspectos climatológicos, a região caracteriza-se, segundo a classificação de Köeppen, pelo tipo Cwa - mesotérmico, de inverno seco, caracterizado por temperaturas médias anuais ligeiramente inferiores a $22{ }^{\circ} \mathrm{C}$, com chuvas típicas 
de clima tropical (LEITE, 1998). A precipitação é marcadamente maior de outubro a abril, sendo o período mais chuvoso de dezembro a fevereiro, tanto em frequência quanto em volume; de maio a setembro, as chuvas reduzem-se sensivelmente. O período de maiores índices pluviométricos predispõe mais os agroecossistemas ao processo de erosão, sobretudo nos meses de outubro, novembro e dezembro, quando o solo está na fase de preparo para o cultivo (ITESP, 1999).

A área do Pontal do Paranapanema está inserida no compartimento geomorfológico denominado Planalto Ocidental, sobre rochas do Grupo Bauru, constituídas por formações predominantemente areníticas. O relevo é uniforme, com predominância de colinas amplas e médias (SMA/SP, 1999). Existem dois tipos predominantes de solos na região: os Latossolos Vermelho-Escuros e os podzólicos que interagem com outras formações em menores proporções. Os solos são, na sua maioria, muito arenosos, pouco ácidos, pobres em argila e de grande profundidade e, consequentemente, de alta drenagem (ATLAS INTERATIVO DO PONTAL DO PARANAPANEMA, 2001). Devido à sua fragilidade natural, manejos apropriados são fundamentais para evitar grandes processos erosivos, o que torna as terras do Pontal aptas apenas a lavouras que requerem pouca mecanização (DITT, 2002). Dentro de um mosaico formado por uma matriz de assentamentos e poucos remanescentes florestais, a área de estudo abrangida por esta pesquisa consiste em uma faixa de Reserva Legal, que se encontrava na forma de pastagem abandonada, cuja recuperação teve início em junho de 2007, pelo método de plantio de mudas. A área possui baixa declividade e é circundada por pequeno fragmento florestal bastante alterado, com 109,52 ha, que juntamente com a área de estudo desta pesquisa compõe a Reserva Legal do assentamento. As mudas provenientes para a restauração dessa área foram adquiridas pelo viveiro da Companhia Energética de São Paulo (CESP). O espaçamento do plantio é de $4 \mathrm{~m} \times 3 \mathrm{~m}$ e as espécies utilizadas foram selecionadas tendo como critério a ocorrência na região, o grupo sucessional e a disponibilidade do viveiro. O total de área restaurada é de 26,75 ha, localizada no Assentamento Nova Esperança, Município de Euclides da Cunha Paulista (Figura 1).
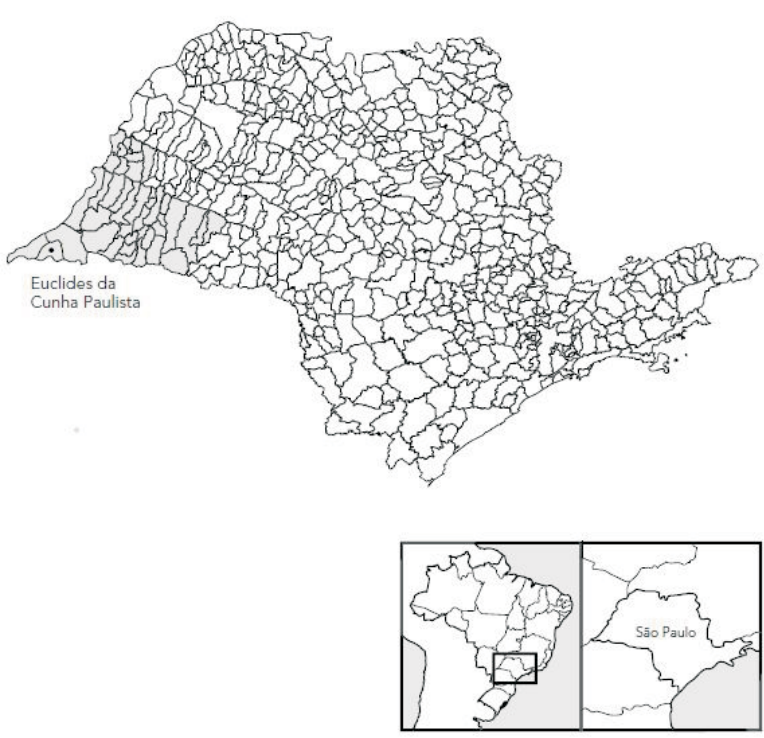

Figura 1 - Região do Pontal do Paranapanema, com destaque para o Município de Euclides da Cunha Paulista.

Figure 1 - Region of Pontal of Paranapanema, highlighting the municipality of Euclides da Cunha Paulista.

\subsection{Delineamento Experimental}

Foram instaladas na área 16 parcelas de 20 m X 30 m com amostragem de todos os indivíduos arbóreos presentes dentro das parcelas em dois momentos distintos: 3 e 18 meses após o plantio das mudas. Alguns parâmetros fitossociológicos comumente utilizados para análises de comunidades florestais foram calculados (DURIGAN e LEITÃO-FILHO, 1995), com o uso do software FITOPAC (SHEPHERD, 1988), sendo eles: Frequência Absoluta (FA), Densidade Absoluta (DA), Frequência Relativa (FR), Densidade Relativa (DR), Valor de Importância (VI) e Valor de Cobertura (VC). A Dominância Absoluta (DoA) e a Relativa (DoR), apesar de comumente utilizadas, não foram adotadas nesta pesquisa pelo fato de o plantio ser recente e os indivíduos arbóreos possuir diâmetro pouco significativo.

A heterogeneidade florística do sítio de amostragem foi calculada pelo índice de diversidade de Shannon (PIELOU, 1984) e a similaridade florística, analisada através do índice de Jaccard (MÜLLER-DOMBOIS; ELLENBERG, 1974), comparando-se o plantio com o levantamento fitossociológico realizado por Schllitler (1995) na região do Pontal do Paranapanema.

Revista Árvore, Viçosa-MG, v.34, n.5, p.853-861, 2010 
A classificação do grupo ecológico das espécies foi feita por meio de consulta bibliográfica (NAPPO, 2004; CARVALHO, 2003; SILVA et al., 2003; PAULA et al., 2002; SOUZA; BATISTA, 2004; LORENZI, 1998; LORENZI, 1992), tendo como base a classificação sugerida por Budowski (1965), que identificou quatro grupos ecológicos funcionais: pioneiras, secundárias iniciais, secundárias tardias e climácicas.

\section{RESULTADOS E DISCUSSÃO}

Foram encontradas, no início desta pesquisa (3 meses após o plantio), 45 espécies distribuídas em 22 famílias botânicas, totalizando 1.389 indivíduos arbóreos vivos. A área amostrada foi de 0,96 ha e a densidade total foi de 1.446,88 árvores/ha, com uma taxa de mortalidade de 20,4\%. O Índice de Diversidade de Shannon foi de 2,716 para espécies e 2.278 para famílias. Os demais parâmetros fitossociológicos se encontram na Tabela 1.

Na segunda análise (18 meses após o plantio), houve redução de 37,5\% no número de indivíduos arbóreos na área, totalizando 868 deles. Sete espécies inicialmente amostradas (Gochnatia polymorpha (Less) Cabrera, Cytharexyllum myrianthum Cham., Cariniana estrelensis (Raddi) Kuntze, Colubrina glandulosa Perk., Cedrela fissilis Vell., Eugenia uniflora L. e Ficus guaranitica Chodat) desapareceram ao final do período, resultando num total de 38 espécies e 20 famílias na área, visto que cinco dessas espécies eram representantes únicas das respectivas famílias.

As cinco famílias mais representativas em números de indivíduos foram, aos três meses e aos 18 meses: Euphorbiaceae, Sterculiaceae, Ulmaceae, Cecropiaceae e Mimosaceae. Juntas, essas famílias possuíam, ao final do período de análise, 489 indivíduos vivos, representando 56,33\% do número total de árvores presentes na área.

De acordo com Santos e Kinoshita (2003), é comum poucas famílias agruparem a maioria das espécies em levantamentos florísticos realizados nesse bioma. Leitão Filho et al. (1998) citaram as famílias Myrtaceae, Fabaceae, Rubiaceae, Eufhobiaceae e Lauraceae como caracteristicamente abundantes nas matas do interior do Estado de São Paulo, conforme 19 trabalhos analisados. O total deste estudo apontou para 75 famílias e 569 espécies presentes em áreas de floresta estacional semidecidual no Estado, mostrando a grande riqueza e diversidade nesse tipo florestal. Entre as famílias citadas por esses autores, somente Eufhobiaceae e Myrtaceae foram encontradas nesta pesquisa.
O índice de diversidade de Shannon ( $\left.\mathrm{H}^{\prime}\right)$ obtido neste levantamento foi de 2,71 para espécies e 2,27 para famílias aos três meses de idade e 2,76 para espécies e 2,33 para famílias aos 18 meses de idade. Apesar da diminuição de espécies e indivíduos aos 18 meses de idade, o índice de Shannon se mostrou relativamente maior. Isso se deve pelo fato de que o índice leva em consideração a abundância das espécies na área e, entre aquelas que desapareceram na segunda fase do levantamento, havia poucos indivíduos representantes nas parcelas, o que não causa muita variação nos valores obtidos.

Por se tratar de grande remanescente florestal localizado na mesma região de abrangência desta pesquisa, compararam-se as famílias e espécies encontradas neste levantamento com o estudo fitossociológico conduzido no Parque Estadual Morro do Diabo (maior reserva de Floresta Estacional Semidecidual do Estado de São Paulo, com cerca de 34 mil hectares, localizado na região do Pontal do Paranapanema) por Schlittler et al. (1995).

Conforme a equação de Jaccard (MÜLLERDOMBOIS; ELLENBERG, 1974), o índice de similaridade obtido, ao final do estudo para famílias, foi de 47,61\%, e para espécies obteve-se o índice de similaridade de 18,25\%. Müller-Dumbois e Ellenberg (1974) afirmaram que remanescentes de mata podem ser considerados semelhantes sempre que apresentarem pelo menos $25 \%$ de concordâncias florísticas. Assim, pode-se afirmar que a área de levantamento desta pesquisa não é semelhante a uma área de vegetação natural, apesar de possuir grande número de espécies representativas do bioma ocorrente. Também, verificou-se a presença de espécies características do bioma de Cerrado, como é o caso de Magonia pubescens St. Hil. (CAMPOS et al., 2006).

No levantamento realizado no Parque Estadual Morro do Diabo, Schlittler et al. (1995) amostraram 111 espécies distribuídas em 42 famílias botânicas. Essa maior riqueza observada no Parque pode ser explicada pela presença de grande número de espécies ocorrendo em baixas densidades, característica comum das Florestas Tropicais (HARTSHORN, 1980), fato pouco comum em áreas restauradas devido à dificuldade operacional, assim como a pouca disponibilidade de mudas.

Souza e Batista (2004) afirmaram que o baixo número de espécies em áreas reflorestadas, justificável pelas dificuldades operacionais, pode ser fator de comprometimento da diversidade da floresta passados 
alguns anos após o plantio, caso não haja colonização razoável por outras espécies. Para tal, a proximidade com possíveis "fontes" (sementes e seus agentes dispersores) é de extrema importância para que novas espécies possam colonizar tais áreas. Viana e Pinheiro (1998) complementaram que o isolamento de fragmentos florestais afeta os fluxos gênicos das populações, que podem ter sua perpetuação comprometida.

A área implantada se encontra próxima ao Parque Estadual Morro do Diabo e pequenos fragmentos florestais distribuídos pela região. Isso pode facilitar a colonização futura da área por novas espécies. No entanto, essa condição não é única: também é preciso avaliar se a área irá garantir seus processos ecológicos mínimos, como polinização, dispersão, regeneração natural e predação natural, fatores essenciais para regeneração e abrigo da fauna como floresta natural (SOUZA; BATISTA, 2004; KAGEYAMA; CASTRO, 1989; LEITÃO FILHO et al., 1998).

Em relação aos grupos ecológicos, das 45 espécies presentes no início do levantamento, 32 espécies (71,11\%) pertencem aos grupos da fase inicial de sucessão, sendo 17 pioneiras (37,77\%) e 15 secundárias iniciais (33,33\%); 13 espécies $(28,88 \%)$ pertencem aos grupos da fase avançada de sucessão, sendo 11 (24,44\%) secundárias tardias e duas $(4,44 \%)$ climácicas (Tabela 1).

Aos 18 meses, o número de espécies estava distribuído nas seguintes proporções dentro de cada grupo ecológico: 28 espécies (73,68\%) pertencem aos grupos iniciais, sendo 15 pioneiras $(39,47 \%)$ e 13 secundárias iniciais (34,21\%); 10 espécies (26,31\%) pertencem aos grupos secundários, sendo nove (23,68\%) secundárias tardias e apenas uma (2,63\%) climácica (Tabela 2). Esses resultados indicam que não houve diferença de mortalidade entre os grupos ecológicos.

Percebeu-se uma elevada proporção de espécies pertencentes aos grupos iniciais de sucessão. De acordo com Kageyama e Gandara (2000), o uso de espécies pioneiras em plantios para fins de restauração cria condições de sombreamento para as espécies dos estágios posteriores de sucessão. O uso de um modelo sucessional na implantação de florestas mistas é a tentativa de dar à regeneração artificial condições semelhantes ao que aconteceria no ambiente naturalmente, onde as espécies pioneiras são a chave que desencadearia as condições adequadas para o desenvolvimento das espécies não pioneiras. Entretanto, uma proporção muito elevada de espécies dos estágios iniciais de sucessão pode comprometer os processos ecológicos futuros na área. Inclusive, a legislação ambiental vigente (Resolução SMA-SP 8, de 31/01/2008) determina que nenhum dos grupos ecológicos (para efeitos dessa lei, os grupos ecológicos são divididos em duas categorias: pioneiros e não pioneiros) ultrapasse $50 \%$ do total de espécies do plantio. No levantamento realizado, o grupo das espécies pioneiras (que envolve, portanto, as espécies pioneiras e secundárias iniciais) ultrapassa 70\% do total de espécies presentes na área.

Essas recomendações visam aproximar as condições de plantio ao que ocorre no ambiente natural. Entretanto, Ivanauskas et al. (1999) obtiveram, em levantamento realizado em área de Floresta Estacional Semidecidual, no Município de Itatinga, SP, resultados distintos das proporções supracitadas. Entre o total de indivíduos amostrados, 5,24\% de espécies tipicamente pioneiras, 40,57\% de espécies secundárias iniciais, 33,12\% de espécies secundárias tardias, 9,64\% de espécies sem caracterização e 11,42\% de árvores mortas. Também, Higuchi et al. (2006) encontraram menor proporção de espécies pioneiras num levantamento da regeneração espontânea de um fragmento de Floresta Estacional Semidecidual em Viçosa, atribuindo ao fechamento do dossel a explicação para o baixo número de espécies pioneiras. Isso mostra a enorme variabilidade que existe na distribuição ecológica das espécies em ambientes naturais.

Vale ressaltar, porém, que a classificação das espécies em grupos ecológicos pode ser variável, uma vez que diferentes autores usam de critérios diferenciados, o que muitas vezes leva uma mesma espécie a ser classificada em grupos distintos. Também, uma mesma espécie pode responder diferentemente, devido à sua variabilidade genética, às condições ambientais como tipologia de solo, clima, regime hídrico (SILVA et al., 2003) ou às condições antrópicas como fogo, desmatamento, agricultura etc. (KAGEYAMA; GANDARA, 2000).

\section{CONCLUSÃO}

Conclui-se que a área restaurada possui espécies adequadas ao bioma ocorrente. A elevada mortalidade dos indivíduos arbóreos ao longo do período analisado indica a necessidade de intervenções nos plantios realizado, pois a redução em número e espécies pode levar a um comprometimento da comunidade arbórea no longo prazo. Recomenda-se o enriquecimento da área com espécies dos grupos secundários de sucessão, para que a área tenha um percentual de espécies dos diferentes grupos ecológicos conforme recomendado pela legislação estadual vigente, e novas análises para avaliar a dinâmica sucessional após o replantio.

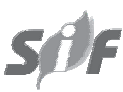

Revista Árvore, Viçosa-MG, v.34, n.5, p.853-861, 2010 
Tabela 1 - Espécies arbóreas amostradas aos três meses na área de reserva legal do assentamento Nova Esperança, por ordem decrescente de VI, em que $\mathrm{N}$ = número de indivíduos; DR = densidade relativa (\%); FR = frequência relativa (\%); FA = frequência absoluta (\%); DA = densidade absoluta (árvores/ha); VI = valor de importância; VC = valor de cobertura; e GE = grupo ecológico.

Table 1 - Arboreal species collected on the three months in the legal reserve area of the Nova Esperança settlement, organized in a decreasing order based on the importance value. when: $N=$ number of individuals; $D R=$ relative density $(\%) ; F R=$ relative frequency $(\%) ; F A=$ absolute frequency $(\%) ; D A=$ absolute density $($ trees/ha $) ; \mathrm{VI}=$ value of importance; $V C=$ value of cover $;$ and $G E=$ ecological group.

\begin{tabular}{|c|c|c|c|c|c|c|c|c|}
\hline ESPÉCIES & $\mathrm{N}$ & $\mathrm{DR}$ & FR & $\mathrm{FA}$ & $\mathrm{DA}$ & VI & $\mathrm{VC}$ & GE \\
\hline Guazuma ulmifolia & 168 & 12,10 & 5,00 & 100,00 & 175,0 & 17,10 & 12,10 & $\mathrm{P}$ \\
\hline Trema micrantha & 147 & 10.58 & 5,00 & 100,00 & 153,1 & 15,58 & 10,58 & $\mathrm{P}$ \\
\hline Croton urucurana & 113 & 8,14 & 4,69 & 93,75 & 117,7 & 12,82 & 8,14 & $\mathrm{P}$ \\
\hline Cecropia pachystachya & 103 & 7,42 & 4,69 & 93,75 & 107,3 & 12,10 & 7,42 & $\mathrm{P}$ \\
\hline Croton floribundus & 90 & 6,48 & 4,69 & 93,75 & 93,8 & 11,17 & 6,48 & $\mathrm{P}$ \\
\hline Peltophorum dubium & 72 & 5,18 & 4,69 & 93,75 & 75,0 & 9,87 & 5,18 & SI \\
\hline Schinus terebentifolius & 27 & 1,94 & 4,06 & 81,25 & 28,1 & 6,01 & 1,94 & $\mathrm{P}$ \\
\hline Inga uruguensis & 31 & 2,23 & 3,75 & 75,00 & 32,3 & 5,98 & 2,23 & $\mathrm{P}$ \\
\hline Anadenanthera macrocarpa & 22 & 1,58 & 4,06 & 81,25 & 22,9 & 5,65 & 1,58 & SI \\
\hline Inga fagifolia & 17 & 1,22 & 4,06 & 81,25 & 17,7 & 5,29 & 1,22 & SI \\
\hline Astronium graviolens & 18 & 1,30 & 3,75 & 75,00 & 18,8 & 5,05 & 1,30 & SI \\
\hline Tabebuia heptaphylla & 21 & 1,51 & 3,13 & 62,50 & 21,9 & 4,64 & 1,51 & SI \\
\hline Anadenanthera colubrina & 11 & 0,79 & 3,13 & 62,50 & 11,5 & 3,92 & 0,79 & SI \\
\hline Acacia polyphylla & 17 & 1,22 & 2,50 & 50,00 & 17,7 & 3,72 & 1,22 & $\mathrm{P}$ \\
\hline Tabebuia impetiginosa & 15 & 1,08 & 2,50 & 50,00 & 15,6 & 3,58 & 1,08 & ST \\
\hline Hymenaea stilbocarpa & 09 & 0,65 & 2,19 & 43,75 & 9,4 & 2,84 & 0,65 & ST \\
\hline Albizia hasslerii & 09 & 0,65 & 2,19 & 43,75 & 9,4 & 2,84 & 0,65 & $\mathrm{P}$ \\
\hline Patagonula americana & 13 & 0,94 & 1,88 & 37,50 & 13,5 & 2,81 & 0,94 & ST \\
\hline Parapiptadenia rigida & 14 & 1,01 & 1,56 & 31,25 & 14,6 & 2,57 & 1,01 & SI \\
\hline Tabebuia chrysotricha & 09 & 0,65 & 1,88 & 37,50 & 9,4 & 2,52 & 0,65 & ST \\
\hline Enterolobium contortisiliquum & 08 & 0,58 & 1,88 & 37,50 & 8,3 & 2,45 & 0,58 & $\mathrm{P}$ \\
\hline Myracrodruon urundeuva & 08 & 0,58 & 1,88 & 37,50 & 8,3 & 2,45 & 0,58 & ST \\
\hline Inga laurina & 07 & 0,50 & 1,88 & 37,50 & 7,3 & 2,38 & 0,50 & SI \\
\hline Triplaris brasiliana & 06 & 0,43 & 1,88 & 37,50 & 6,3 & 2,31 & 0,43 & SI \\
\hline Gallesia integrifolia & 06 & 0,43 & 1,88 & 37,50 & 6,3 & 2,31 & 0,43 & SI \\
\hline Guarea guidonia & 08 & 0,58 & 1,56 & 31,25 & 8,3 & 2,14 & 0,58 & $\mathrm{C}$ \\
\hline Colubrina glandulosa & 07 & 0,50 & 1,56 & 31,25 & 7,3 & 2,07 & 0,50 & SI \\
\hline Jacaratia spinosa & 05 & 0,36 & 1,25 & 25,00 & 5,2 & 1,61 & 0,36 & $\mathrm{P}$ \\
\hline Phytolacca dioica & 05 & 0,36 & 1,25 & 25,00 & 5,2 & 1,61 & 0,36 & $\mathrm{P}$ \\
\hline Eugenia uniflora & 04 & 0,29 & 1,25 & 25,00 & 4,2 & 1,54 & 0,29 & ST \\
\hline Ruprechtia lanceolata & 06 & 0,43 & 0,94 & 18,75 & 6,3 & 1,37 & 0,43 & SI \\
\hline Chorisia speciosa & 05 & 0,36 & 0,94 & 18,75 & 5,2 & 1,30 & 0,36 & $\mathrm{P}$ \\
\hline Cariniana estrellensis & 04 & 0,29 & 0,94 & 18,75 & 4,2 & 1,23 & $0,29 \mathrm{~S}$ & ST \\
\hline Ficus guaranitica & 03 & 0,22 & 0,94 & 18,75 & 3,1 & 1,15 & 0,22 & SI \\
\hline Alophyllus edulis & 03 & 0,22 & 0,63 & 12,50 & 3,1 & 0,84 & 0,22 & $\mathrm{P}$ \\
\hline Cedrella fissilis & 03 & 0,22 & 0,63 & 12,50 & 3,1 & 0,84 & 0,22 & $\mathrm{C}$ \\
\hline Magonia pubescen & 02 & 0,14 & 0,63 & 12,50 & 2,1 & 0,77 & 0,14 & ST \\
\hline Pterogyne nitens & 02 & 0,14 & 0,63 & 12,50 & 2,1 & 0,77 & 0,14 & ST \\
\hline Psidium guajava & 02 & 0,14 & 0,63 & 12,50 & 2,1 & 0,77 & 0,14 & $\mathrm{P}$ \\
\hline Casearia sylvestris & 02 & 0,14 & 0,63 & 12,50 & 2,1 & 0,77 & 0,14 & SI \\
\hline Myrciaria tenella & 02 & 0,14 & 0,63 & 12,50 & 2,1 & 0,77 & 0,14 & SI \\
\hline Cordia trichotoma & 01 & 0,07 & 0,31 & 06,25 & 1,0 & 0,38 & 0,07 & ST \\
\hline Gochnatia polymorpha & 01 & 0,07 & 0,31 & 06,25 & 1,0 & 0,38 & 0,07 & $\mathrm{P}$ \\
\hline Cytharexyllum myrianthum & 01 & 0,07 & 0,31 & 06,25 & 1,0 & 0,38 & 0,07 & $\mathrm{P}$ \\
\hline Casearia gossypiosperma & 01 & 0,07 & 0,31 & 06,25 & 1,0 & 0,38 & 0,07 & ST \\
\hline
\end{tabular}

$\mathrm{P}$ = pioneira; $\mathrm{SI}$ = secundária inicial; $\mathrm{ST}$ = secundária tardia; e C = clímax.

Revista Árvore, Viçosa-MG, v.34, n.5, p.853-861, 2010 
Tabela 2 - Espécies arbóreas amostradas aos 18 meses na área de reserva legal do assentamento Nova Esperança, por ordem decrescente de VI, em que $\mathrm{N}$ = número de indivíduos; DR = densidade relativa (\%); FR = frequência relativa (\%); FA = frequência absoluta (\%); DA = densidade absoluta (árvores/ha); VI = valor de importância; VC = valor de cobertura; e GE = grupo ecológico.

Table 2 - Arboreal species collected on the eighteen months in the legal reserve area of the Nova Esperança settlement, organized in a decreasing order based on the importance value. when: $N=$ number of individuals; $D R=$ relative density (\%); FR = relative frequency (\%); FA = absolute frequency (\%);DA = absolute density (trees/ha); $V I=$ value of importance VC = value of cover $;$ and $G E=$ ecological group.

\begin{tabular}{|c|c|c|c|c|c|c|c|c|}
\hline ESPÉCIES & $\mathrm{N}$ & $\mathrm{DR}$ & FR & FA & $\mathrm{DA}$ & IVI & IVC & GE \\
\hline Guazuma ulmifolia & 99 & 11,41 & 4,95 & 100,00 & 150,0 & 16,36 & 11,41 & $\mathrm{P}$ \\
\hline Trema micrantha & 94 & 10,83 & 4,95 & 100,00 & 142,4 & 15,78 & 10,83 & $\mathrm{P}$ \\
\hline Cecropia pachystachya & 88 & 10,14 & 4,95 & 100,00 & 133,3 & 15,09 & 10,14 & $\mathrm{P}$ \\
\hline Croton urucurana & 67 & 7,72 & 4,95 & 100,00 & 101,5 & 12,67 & 7,72 & $\mathrm{P}$ \\
\hline Croton floribundus & 68 & 7,83 & 4,50 & 90,91 & 103,0 & 12,34 & 7,83 & $\mathrm{P}$ \\
\hline Peltophorum dubium & 42 & 4,84 & 4,95 & 100,00 & 63,6 & 9,79 & 4,84 & SI \\
\hline Schinus terebentifolius & 20 & 2,30 & 4,05 & 81,82 & 30,3 & 6,36 & 2,30 & $\mathrm{P}$ \\
\hline Anadenanthera macrocarpa & 14 & 1,61 & 4,05 & 81,82 & 21,2 & 5,67 & 1,61 & SI \\
\hline Tabebuia heptaphylla & 17 & 1,96 & 3,15 & 63,64 & 25,8 & 5,11 & 1,96 & SI \\
\hline Astronium graviolens & 13 & 1,50 & 3,60 & 72,73 & 19,7 & 5,10 & 1,50 & SI \\
\hline Inga uruguensis & 14 & 1,61 & 3,15 & 63,64 & 21,2 & 4,77 & 1,61 & $\mathrm{P}$ \\
\hline Inga fagifolia & 10 & 1,25 & 3,60 & 72,73 & 15,2 & 4,76 & 1,15 & SI \\
\hline Acacia polyphylla & 08 & 0,92 & 2,70 & 54,55 & 12,1 & 3,62 & 0,92 & $\mathrm{P}$ \\
\hline Anadenanthera colubrina & 07 & 0,81 & 2,70 & 54,55 & 10,6 & 3,51 & 0,81 & SI \\
\hline Triplaris brasiliana & 06 & 0,69 & 2,70 & 54,55 & 9,1 & 3,39 & 0,69 & SI \\
\hline Tabebuia impetiginosa & 07 & 0,81 & 2,25 & 45,45 & 10,6 & 3,06 & 0,81 & $\mathrm{ST}$ \\
\hline Hymenaea stilbocarpa & 07 & 0,81 & 2,25 & 45,45 & 10,6 & 3,06 & 0,81 & ST \\
\hline Enterolobium contortisiliquum & 07 & 0,81 & 2,25 & 45,45 & 10,6 & 3,06 & 0,81 & $\mathrm{P}$ \\
\hline Myracrodruon urundeuva & 07 & 0,81 & 2,25 & 45,45 & 10,6 & 3,06 & 0,81 & ST \\
\hline Patagonula americana & 08 & 0,92 & 1,80 & 36,36 & 12,1 & 2,72 & 0,92 & ST \\
\hline Phytolacca dioica & 05 & 0,58 & 1,80 & 36,36 & 7,6 & 2,38 & 0,58 & $\mathrm{P}$ \\
\hline Inga laurina & 04 & 0,46 & 1,80 & 36,36 & 6,1 & 2,26 & 0,46 & SI \\
\hline Gallesia integrifolia & 04 & 0,46 & 1,80 & 36,36 & 6,1 & 2,26 & 0,46 & SI \\
\hline Parapiptadenia rigida & 06 & 0,69 & 1,35 & 27,27 & 9,1 & 2,04 & 0,69 & SI \\
\hline Guarea guidonia & 05 & 0,58 & 1,35 & 27,27 & 7,6 & 1,93 & 0,58 & C \\
\hline Tabebuia chrysotricha & 05 & 0,58 & 1,35 & 27,27 & 7,6 & 1,93 & 0,58 & ST \\
\hline Jacaratia spinosa & 03 & 0,35 & 1,35 & 27,27 & 4,5 & 1,70 & 0,35 & $\mathrm{P}$ \\
\hline Albizia hasslerii & 03 & 0,35 & 1,35 & 27,27 & 4,5 & 1,70 & 0,35 & $\mathrm{P}$ \\
\hline Alophyllus edulis & 03 & 0,35 & 0,90 & 18,18 & 4,5 & 1,25 & 0,35 & $\mathrm{P}$ \\
\hline Magonia pubescens & 02 & 0,23 & 0,90 & 18,18 & 3,0 & 1,13 & 0,23 & ST \\
\hline Ruprechtia lanceolata & 02 & 0,23 & 0,90 & 18,18 & 3,0 & 1,13 & 0,23 & SI \\
\hline Pterogyne nitens & 02 & 0,23 & 0,90 & 18,18 & 3,0 & 1,13 & 0,23 & ST \\
\hline Psidium guajava & 02 & 0,23 & 0,90 & 18,18 & 3,0 & 1,13 & 0,23 & $\mathrm{P}$ \\
\hline Casearia sylvestris & 02 & 0,23 & 0,90 & 18,18 & 3,0 & 1,13 & 0,23 & SI \\
\hline Myrciaria tenella & 02 & 0,23 & 0,90 & 18,18 & 3,0 & 1,13 & 0,23 & SI \\
\hline Cordia trichotoma & 01 & 0,12 & 0,45 & 9,09 & 1,5 & 0,57 & 0,12 & ST \\
\hline Chorisia speciosa & 01 & 0,12 & 0,45 & 9,09 & 1,5 & 0,57 & 0,12 & $\mathrm{P}$ \\
\hline Casearia gossypiosperma & 01 & 0,12 & 0,45 & 9,09 & 1,5 & 0,57 & 0,12 & ST \\
\hline
\end{tabular}

$\mathrm{P}$ = pioneira; SI = secundária inicial; ST = secundária tardia; e C = clímax.

\section{REFERÊNCIAS}

ANAND, M.; DESROCHERS, R.E. Quantification of restoration success using complex systems concepts and models. Restoration Ecology v. 12, n.1, p. 117-123, 2000.

\section{ATLAS INTERATIVO DO PONTAL DO}

PARANAPANEMA, 2001. Disponível em

$<$ www.multimidia.prudente.unesp.br/atlaspontal>

Consulta em 12/02/2007. 
BUDOWSKI, G. Distribuition of tropical American raisforest in the light of sucessional process. Turrialba. v.15, n.1, p. 40-42, 1965.

CAMPOS, E. P. Composição florística de um trecho de cerradão e cerrado senso stricto e sua relação com o solo na Floresta Nacional (FLONA) de Paraopeba, MG, Brasil. Revista Árvore. v. 30, n. 3, p. 471-479, 2006.

\section{CARVAlHO, P. E. R. Espécies Arbóreas} Brasileiras. Colombo: EMBRAPA-Florestas, vol 1, 2003.

DITT, E. H. Fragmentos Florestais no Pontal do Paranapanema. Ed. Anna Blumme, 2002.

DURIGAN, G. e LEITÃO FILHO, H. F. Florística e fitossociologia de matas ciliares do Oeste Paulista. Revista do Instituto Florestal. v. 7, n. 2, p. 197-239, 1995.

DURIGAN, G. et al. Estrutura e diversidade do componente arbóreo da floresta na Estação Ecológica dos Caetetus, Gália, SP. Revista Brasileira de Botânica. São Paulo, v. 4, n. 23, p.369-381,2000.

ENGEL, V. L. e J. A. PARROTTA. An Evaluation of Direct Seedling for

Reforestation of Degraded Lands in Central São Paulo State, Brazil. Forest Ecology

Manegement. v. 152 , n. 1-3, p. 169-181, 2001.

FERREIRA, W. C. et al. Avaliação do crescimento do estrato arbóreo de área degradada revegetada à margem do Rio Grande. Revista Árvore, v. 31, n.1 p. 177-185, 2007.

HARTSHORN, G. S. Neotropical forest dinamics. Revista Biotrópica. v.12, p.23-30, 1980.

HIGUCHI, P. et.al. Composição florística da regeneração natural de espécies arbóreas ao longo de oito anos em um fragmento de floresta estacional semidecidual em Viçosa, MG. Revista Árvore. v. 30, n. 6, p. 893-204, 2006.

ITESP (INSTITUTO DE TERRAS DO ESTADO DE SÃO PAULO). Pontal Verde: plano de recuperação ambiental nos assentamentos do Pontal do Paranapanema Cadernos Itesp. N. 2, $2^{\circ}$ edição. São Paulo: ITESP/Secretaria da Justiça e da Defesa da Cidadania, 1999.

Revista Árvore, Viçosa-MG, v.34, n.5, p.853-861, 2010
IVANAUSKAS, N.M.; RODRIGUES, R.R. e NAVE, A.G. Fitossociologia de um trecho de Floresta Estacional Semidecidual em Itatinga, SP, Brasil. Scientia Forestalis. n. 56, p. 83-99, 1999

KAGWEYAMA, P.Y. e CASTRO, C.F.A. Sucessão secundária, estrutura genética e plantações de espécies arbóreas nativas. IPEF. n.41-42, 1989.

KAGEYAMA, P. Y. e GANDARA, F.B.

Recuperação de áreas ciliares. In: RODRIGUES, R. R.; LEITÃO FILHO, H. Matas ciliares: conservação e recuperação. São Paulo: USP/Fapesp, 2000. p.249-269.

LEITÃO-FILHO, H. F. et al. Vegetação Florestal Remanescente: Inventários, caracterização, manejo e recuperação nas bacias dos Rios Piracicaba e Capivari. In:Qualidade ambiental e desenvolvimento regional nas bacias do Rio Piracicaba e Capivari. Cadernos $\mathrm{n}^{\circ} 7$, Campinas: NEPAM, 1998.

Leite, J. F. A ocupação do Pontal do Paranapanema. São Paulo: Hucitec, 1998.

LORENZI, H. Árvores brasileiras: manual de identificação e cultivo de plantas arbóreas nativas do Brasil. Nova Odessa: Plantarum, 1992. v. 1.

LORENZI, H. Árvores brasileiras: manual de identificação e cultivo de plantas arbóreas nativas do Brasil. Nova Odessa: Plantarum, 1998. volume 2.

METZGER, J. P. Estrutura da paisagem e fragmentação: uma análise bibliográfica. Anais Academia Brasileira de Ciências, v. 71, n.3, p.445-463, São Paulo, 1999.

MÜLLER-DUMBOIS, D. e ELLENBERG, H. Aimms and methods of vegetation ecology. John Wiley \& Sons: New York, 1974.

PAULA, A. et. al. Alterações florísticas ocorridas num período de quatorze anos na vegetação arbórea de uma floresta estacional semidecidual em Viçosa, MG. Revista Árvore. v.26, n.6, p.743-749, 2002.

PIELOU, E. C. The interpretation of ecological data: a primer on classification and ordination. John Wiley \& Sons: New York, 1984 
MYERS, N. et.al. Biodiversity hotspots for conservation priorities. Nature, v. 403, p. 853-858, 2000.

NAPPO, M. E. Dinâmica da estrutura fitossociológica da regeneração natural em subbosque de Momosa scabrella Bentham em área minerada, em Poços de Caldas, MG. Revista Árvore. v. 28, n. 6, p. 811-829, 2004.

REIS, A.; ZAMBONIN, R. M. e NAKAZONO, E. $M$. Recuperação de áreas degradadas utilizando a sucessão e as interações planta-animal. São Paulo: Cetesb, 1999.

RODRIGUES, R. R.; GANDOLFI, S. Conceitos, tendências e ações para a recuperação de florestas ciliares. In: RODRIGUES, R. R.; LEITÃO FILHO, H. Matas ciliares: conservação e recuperação. São Paulo: USP/Fapesp, 2000. p. 235-247.

SANTOS, K e KINOSHITA, L.S. Flora arbustivoarbórea do fragmento de floresta estacional semidecidual do Ribeirão Cachoeira, município de Campinas, SP. Revista Acta Botanica Brasílica. v.17, n.3, p.325-341, 2003.

SCHLITTLER, F. H. M. et.al.. Estudos Fitossociológicos Na Floresta do Morro do Diabo (Pontal do Paranapanema,Sp). Arquivos de Biologia e Tecnologia. v. 38, n. 1, p. 217-234, 1995.
SHEPHERD, G. J. FITOPAC 1. Manual do usuário. Departamento de Botânica. Instituto de Biologia, Universidade Estadual de Campinas, Campinas, 1988.

SILVA, A.F. et. al. Composição florística e grupos ecológicos das espécies de um trecho de floresta semidecídua submontana da fazenda São Geraldo, Viçosa, MG. Revista Árvore. v. 27, n.3, p. 311-319, 2003.

\section{SMA-SP (SECRETARIA DE MEIO AMBIENTE DE} SÃo PAUlo). Pontal do

Paranapanema: zoneamento ecológicoeconômico. São Paulo: SMA/SP, 1999.

SOUZA, F. M. ; BATISTA, J. L. F. . Restoration of Seasonal Semideciduous Forests in Brazil: influence of age and restoration design on forest structure. Forest Ecology and Management, v. 191, n. 1-3, p. 185-200, 2004.

VALLADARES-PÁDUA, C. et. al., Módulos Agroflorestais na conservação de fragmentos florestais da Mata Atlântica. Revista Experiências PDA. Brasília, v. 2, p. 7-33, 2002.

VIANA, V. e PINHEIRO, L. A. F. V. Conservação da biodiversidade em fragmentos florestais. Série Técnica IPEF, v. 12, n. 32, p. 25-42, 1998. 